ORIGINAL ARTICLE

\title{
Combination of Dexmedetomidine and Bupivacaine for Caudal Anesthesia In Children
}

NASIBOVA E.M., POLUXOVR.SH.

Azerbaijan Medical University, Baku.

Correspondence to Nasibova EM, Eail: doc.nasibova.esmira@gmail.com.)

\begin{abstract}
Background: Caudal anesthesia is one of the most popular, reliable and safe methods of pain relief in children and can provide pain relief for various surgical procedures below the navel.

Aim: To evaluate the efficacy and safety of the caudal use of dexmedetomidine in caudal anesthesia in children.

Methods: The subject of the study was 46 children with physical status I and II class of the American Society of Anesthesiologists (ASA), aged 0 to 12 years, who underwent elective surgeries below the navel, such as hernia repair, orchiopexy, hypospadias repair, epispadias, etc.

Results: The duration of caudal analgesia was determined from the moment the anesthetic was injected until the moment the child first complained of pain or the time when the first postoperative analgesia was required. The average duration of postoperative caudal analgesia in patients of group A was $4.21 \pm 0.88$, while in patients of group $B$ this duration was $10.18 \pm 0.85$ hours.

Conclusions. Our results show that the addition of dexmedetomidine to the local anesthetic for caudal block significantly increases the duration of analgesia and reduces the need for analgesics. More data is also needed on the neurological safety of dexmedetomidine.

Key words: dexmedetomidine,caudal block, bupivacaine.
\end{abstract}

\section{INTRODUCTION}

Caudal anesthesia is one of the most popular, reliable and safe methods of pain relief in children and can provide pain relief for various surgical procedures below the navel.The main disadvantage of the caudal block is the short duration of action after a single injection.Increasing the duration of the caudal block with various adjuvants remains relevant to this day.

The objective of the study is too evaluate the efficacy and safety of the caudal use of dexmedetomidine in caudal anesthesia in children.

\section{MATERIAL AND METHODS}

The subject of the study was 46 children with physical status I and II class of the American Society of Anesthesiologists (ASA), aged 0 to 12 years, who underwent elective surgeries below the navel, such as hernia repair, orchiopexy, hypospadias repair, epispadias, etc.Written informed consent for anesthesia was obtained from the parents prior to the operation.Standard monitors such as electrocardiogram, pulse oximeter and noninvasive blood pressure (BP) were used.

Results: All children over 6 months of age were premedicated with midazolam $0.4 \mathrm{mg} / \mathrm{kg}$ orally $20-30$ minutes before the start of the operation.In the presence of parents, children over the age of 6 months were injected intravenously with propofol at a dose of $2 \mathrm{mg} / \mathrm{kg}$ in a preoperative service, and the child was brought to the operating unit in a half-asleep state.After monitoring, the patient was transferred to the left block, and after additional intravenous administration of propofol, the caudal block was started. In the process of anesthesia, all patients received oxygen inhalation of $2 \mathrm{ml} /$ hour. During the entire period of the operation, sedation was carried out with propofol at the rate of $3 \mathrm{mg} / \mathrm{kg} / \mathrm{h}$ using a perfuser.
Caudal blockade was performed with aseptic and antiseptic precautions. Depending on the drug administered, the patients were divided into two groups:

Group A: bupivacaine $2.5 \mathrm{mg} / \mathrm{kg}$ + saline $1.2 \mathrm{ml} / \mathrm{kg}$.

Group B: bupivacaine $2.5 \mathrm{mg} \mathrm{/} \mathrm{kg}+1 \mu \mathrm{g} / \mathrm{kg}$ dexmedetomidine + saline $1.2 \mathrm{ml} / \mathrm{kg}$.

\section{RESULTS}

In our practice, we adhered to a new technique for conducting the caudal block, the so-called "the no turn technique", which consists in puncturing the sacrococcygeal ligament at an angle of 60 degrees without advancing the needle into the sacral canal. This technique, proposed and studied by us, made it possible to conduct a caudal block in $100 \%$ of cases of its application, in contrast to the classical one, where the percentage of successful punctures was $85 \%$. For puncture of the caudal space, we used either conventional 19-21G intramuscular needles or Epican needles. Heart rate (HR), BP and oxygen saturation were recorded before induction and then immediately after caudal anesthesia and every 10 minutes during surgery thereafter. Adequate analgesia was defined as hemodynamic stability, as indicated by the absence of an increase in systolic blood pressure or heart rate of more than $20 \%$ compared to baseline. A decrease in mean arterial pressure $>30 \%$ was defined as hypotension and was treated with intravenous fluids / ephedrine injections. A decrease in heart rate> $30 \%$ was considered as bradycardia and was treated with $0.01 \mathrm{mg} / \mathrm{kg}$ atropine injection. All patients were followed up for 2 hours in the postoperative ward before returning to the ward. HR, BP, RR were monitored constantly. Postoperative pain was assessed 30 minutes $1,2,4,6,8,10,12,18$ and 24 hours after recovery from anesthesia on the FLACC scale. The duration of pain relief (time from caudal block to the first dose of the required analgesic) was recorded. 
Postoperative analgesia in demand was prescribed in the form of a paracetamol $10 \mathrm{mg} / \mathrm{kg}$ suppository. In the postoperative period, the time of onset of pain and the total number of analgesics administered in 24 hours were recorded in all groups. All observations were recorded and all results were analyzed. Statistically, data were presented as mean \pm standard deviation. A $P$ value $<0.05$ was considered a statistically significant difference with the unpaired Student's t-test.

\section{DISCUSSION}

The duration of caudal analgesia was determined from the moment the anesthetic was injected until the moment the child first complained of pain or the time when the first postoperative analgesia was required. The average duration of postoperative caudal analgesia in patients of group $A$ was $4.21 \pm 0.88$, while in patients of group $B$ this duration was $10.18 \pm 0.85$ hours. This shows that the duration was significantly increased by the addition of dexmedetomidine to bupivacaine $(P<0.0001)$. Patients in group $B$ required significantly fewer additional analgesics than in group $A$. In group $A$, all patients required 2 or more analgesic injections within 24 hours. The mean FLACC pain score was lower in Group B patients during the first 24 hours postoperatively. The mean FLACC score in group $A$ was $7.38 \pm 1.61$, and in group $B-6.19 \pm 1.22$. The results are comparable and statistically significant $(P<0.0001)$. The addition of caudal dexmedetomidine $1 \mathrm{mcg} / \mathrm{kg}$ to bupivacaine increased the duration of analgesia compared to simple bupivacaine $2.5 \mathrm{mg} / \mathrm{kg}$ without increasing side effects in children who underwent surgery below the navel.

\section{CONCLUSIONS}

Our results show that the addition of dexmedetomidine to the local anesthetic for caudal block significantly increases the duration of analgesia and reduces the need for analgesics. More data is also needed on the neurological safety of dexmedetomidine.

\section{REFERENCES}

1. Singh $R$, Kumar $N$, Singh $P$. Randomized controlled trial comparing morphine or clonidine with bupivacaine for caudal analgesia in children undergoing upper abdominal surgery. $\mathrm{Br}$ J Anaesth. 2011;106:96-100.

2. Shukla U, Prabhakar T, Malhotra K. Postoperative analgesia in children when using clonidine or fentanyl with ropivacaine given caudally. J AnaesthesiolClinPharmacol. 2011;27:20510.

3. oshi W, Connelly NR, Freeman K, Reuben SS. Analgesic effect of clonidine added to bupivacaine $0.125 \%$ in paediatric caudal blockade. PaediatrAnaesth. 2004;14:483-6.

4. Al-Zaben KR, Qudaisat IY, Abu-Halaweh SA, Al-Ghanem SM, Al-Mustafa MM, Alja'bari AN, et al. Comparison of caudal bupivacaine alone with bupivacaine plus two doses of dexmedetomidine for postoperative analgesia in pediatric patients undergoing infra-umbilical surgery: A randomized controlled double-blinded study. PediatrAnaesth. 2015;25:883-90.

5. Anand VG, Kannan M, Thavamani A, Bridgit MJ. Effect of dexmedetomidine on caudal ropivacaine in pediatric lower abdominal surgeries. Indian J Anaesth. 2011;55:340-6.

6. Saadawy I, Boker A, Elshahawy MA, Almazrooa A, Melibary $S$, Abdellatif $A A$, et al. Effect of dexmedetomidine on the characteristics of bupivacaine in a caudal block in pediatrics. ActaAnaesthesiol Scand. 2009;53:251-6.

7. El-Hennawy AM, Abd-Elwahab AM, Abd-Elmaksoud AM, ElOzairy HS, Boulis SR. Addition of clonidine or dexmedetomidine to bupivacaine prolongs caudal analgesia in children. Br J Anaesth. 2009;103:268-74.

8. Xiang Q, Huang DY, Zhao YL, Wang GH, Liu YX, Zhong L, et al. Caudal dexmedetomidine combined with bupivacaine inhibit the response to hernial sac traction in children undergoing inguinal hernia repair. $\mathrm{Br} J$ Anaesth. 2013;110:420-4.

9. Fares $\mathrm{KM}$, Othman $\mathrm{AH}$, Alieldin $\mathrm{NH}$. Efficacy and safety of dexmedetomidine added to caudal bupivacaine in pediatric major abdominal cancer surgery. Pain Physician. 2014;17:393-400.

10. Tong Y, Ren H, Ding X, Jin S, Chen Z, Li Q. Analgesic effect and adverse events of dexmedetomidine as additive for pediatric caudal anesthesia: A meta-analysis. PaediatrAnaesth. 2014;24:1224-30. 